\section{Commentary: The proximal descending aorta is a "cruel mistress" and should not be ignored}

\section{Andrea J. Carpenter, MD, PhD}

Recent years have seen a shift in the treatment of acute type A dissections toward more extensive repair from grafting the ascending aorta only to open distal anastomoses, hemiarch repair, total arch repair, and elephant trunk. Berdajs and colleagues ${ }^{1}$ present a compelling addition to the literature and a technique that is increasingly available and reproducible. This technique is more available because hospitals where aortic surgery is performed now keep a significant stock of aortic graft inventory and is more reproducible because the described modified frozen elephant trunk places the more challenging distal anastomosis in the native hemiarch area.

The Achilles' heel of aortic arch repair has long been the proximal descending aorta, which is prone to progressive aneurysmal dilation of the false lumen resulting in the progressive collapse of the true lumen. Consider the evolution in the management of type B dissection, which is essentially what we leave after repair of the ascending aorta \pm some measure of arch reconstruction. The INSTEAD ${ }^{2,3}$ and $\mathrm{ADSORB}^{4}$ trials offered rare randomized trials to compare optimal medical therapy (OMT) with OMT plus thoracic endovascular aortic repair (TEVAR). These trials demonstrated that OMT + TEVAR is safe ${ }^{2,4}$ in acute dissection with no difference in short-term outcomes. When these patients are followed 2 to 5 years, there is improved aortaspecific survival and delayed disease progression. ${ }^{3}$ These reports raise the questions whether all type $\mathrm{A}$ dissections should include management of the proximal descending aorta and what is the best technique to accomplish the task.

From Thoracic Surgery, University of Texas Long School of Medicine, San Antonio, Tex.

Disclosures: The author reported no conflicts of interest.

The Journal policy requires editors and reviewers to disclose conflicts of interest and to decline handling or reviewing manuscripts for which they may have a conflict of interest. The editors and reviewers of this article have no conflicts of interest.

Received for publication June 16, 2020; revisions received June 16, 2020; accepted for publication June 16, 2020; available ahead of print July 4, 2020.

Address for reprints: Andrea J. Carpenter, MD, PhD, Department of Cardiothoracic Surgery, 7703 Floyd Curl Dr, MC 7841, San Antonio, TX 78229 (E-mail: carpentera2@uthscsa.edu).

J Thorac Cardiovasc Surg 2022;163:1762-3

$0022-5223 / \$ 36.00$

Copyright (c) 2020 by The American Association for Thoracic Surgery

https://doi.org/10.1016/j.jtcvs.2020.06.085

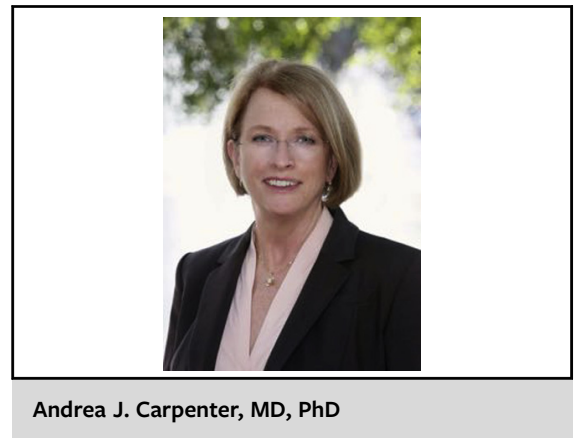

CENTRAL MESSAGE

In treating type A aortic dissection, the proximal descending aorta should not be ignored.

To assess when to treat the descending aorta at the time of acute type A dissection, we need to understand that not all dissections are created equal and define the characteristics that warrant early treatment of the descending aorta. At present, there is inadequate evidence for specific guidelines. Review of type $B$ dissections suggests that the size of the aorta at presentation, the size of the false lumen compared with true lumen, and the number of branches arising from the false lumen may be indicators of poor outcome if untreated. ${ }^{5,6}$

To approach the treatment of the descending aorta, we must consider conditions at the time of presentation. The modified frozen elephant trunk has appeal when the stent can be placed to exclude any entry within the arch. More extensive resection of the arch and frozen elephant trunk could be a better choice if needed to exclude all entry tears within the arch. Serial procedures to repair the ascending aorta and follow with transfemoral TEVAR may be a better choice if the arch has no entry tear and limiting circulatory arrest time is desirable. Surgeons should fill their skill box with all the tools, consider the options in each situation, and choose the best for each patient. Rarely should the proximal descending aorta be ignored.

\section{References}

1. Berdajs DA, Koechlin L, Reid G, Grob F, Gahl B, Schurr U, et al. Modified frozen elephant trunk procedure as standard approach in acute type A aortic dissection: a propensity-weighted analysis. J Thorac Cardiovasc Surg. 2022;163:1754-61.e3.

2. Nienaber CA, Kische S, Akin I, Rousseau H, Eggebrecht H, Fattori R, et al. Strategies for subacute/chronic type B aortic dissection: the investigation of stent grafts in patients with type B aortic dissection (INSTEAD) trial 1-year outcome. J Thorac Cardiovasc Surg. 2010;140(6 Suppl):S101-46.

3. Nienaber CA, Kische S, Rousseau H, Eggebrecht H, Rehders EC, Kundt G, et al. Endovascular repair of type B aortic dissection: long-term results of the 
randomized investigation of stent grafts in aortic dissection trial. Circ Cardiovasc Interv. 2013;6:407-16.

4. Brunkwall J, Kasprzak P, Verhoeven E, Heijmen R, Taylor P, ADSORB Trialists, et al. Endovascular repair of acute uncomplicated aortic type B dissection promotes aortic remodelling: 1 year results of the ADSORB trial [published correction appears in Eur J Vasc Endovasc Surg. 2015;50:130. Böckler D [removed]; von Tenng-Kobligk H [corrected to von Tengg-Kobligk H]]. Eur J Vasc Endovasc Surg. 2014;48:285-91.
5. Kamman AV, Brunkwall J, Verhoeven EL, Heijmen RH, Trimarchi S, ADSORB trialists. Predictors of aortic growth in uncomplicated type B aortic dissection from the acute dissection stent grafting or best medical treatment (ADSORB) database. J Vasc Surg. 2017;65:964-71.e3.

6. Spinelli D, Benedetto F, Donato R, Piffaretti G, Marrocco-Trischitta MM Patel HJ, et al. Current evidence in predictors of aortic growth and events in acute type B aortic dissection. J Vasc Surg. 2018;68:1925-35.e8.
See Article page 1754

\section{Commentary: Modified frozen elephant trunk}

\author{
Reilly Hobbs, MD, MBS, and Ming-Sing Si, MD
}

Advances in the management of patients with acute type A aortic dissection have led to improved survival in this complicated cohort of patients. A study from the International Registry of Acute Aortic Dissections has shown that surgical mortality decreased from $25 \%$ to $18.4 \%$ over the last 2 decades, whereas mortality with medical management has remained relatively static. ${ }^{1}$ As survival has improved, more focus is being placed on strategies to decrease long-term morbidity and the need for reintervention after type A dissection repair. A significant number of patients will develop distal aortic pathology after type A dissection repair, especially if there is residual patent false lumen, connective tissue disease, intimal tears, and dilation beyond $4 \mathrm{~cm}$ in the descending aorta. $^{2}$ The frozen elephant trunk technique has been increasingly used to prevent distal aortic dilation and promote positive aortic remodeling over time. ${ }^{3}$ A frozen elephant trunk during type A dissection repair requires a total or partial arch replacement and deployment of an antegrade stent graft. A potential shortcoming of this technique is the necessity of a complex arch replacement in patients who may otherwise be better served with a more expedient hemiarch replacement.

Berdajs and colleagues ${ }^{4}$ have published their results using a modified frozen elephant trunk technique as their standard

\footnotetext{
From the Section of Pediatric Cardiovascular Surgery, Department of Cardiac Surgery, University of Michigan, Ann Arbor, Mich.

Disclosures: The authors reported no conflicts of interest.

The Journal policy requires editors and reviewers to disclose conflicts of interest and to decline handling or reviewing manuscripts for which they may have a conflict of interest. The editors and reviewers of this article have no conflicts of interest.

Received for publication May 21, 2020; revisions received May 21, 2020; accepted for publication May 21, 2020; available ahead of print June 17, 2020.

Address for reprints: Ming-Sing Si, MD, 11-735 C.S. Mott Children's Hospital SPC 4204, 1540 E Hospital Drive, Ann Arbor, MI 48109-4204 (E-mail: mingsing@ umich.edu).

J Thorac Cardiovasc Surg 2022;163:1763-4

$0022-5223 / \$ 36.00$

Copyright (c) 2020 by The American Association for Thoracic Surgery

https://doi.org/10.1016/j.jtcvs.2020.05.094
}

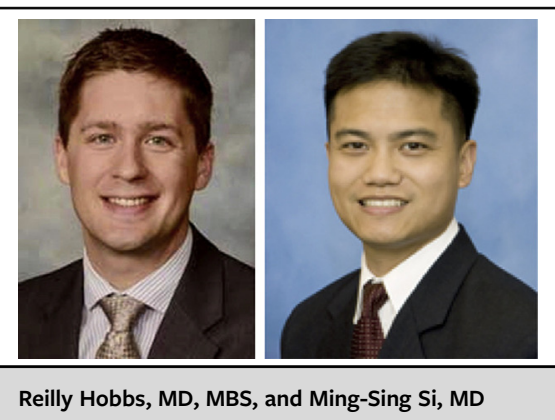

CENTRAL MESSAGE

A modification of the frozen elephant trunk may simplify the treatment of type A aortic dissection.

approach to acute type A dissection repair. In this modified technique, the authors perform a hemiarch replacement with deployment of an antegrade stent graft distal to the left subclavian artery. The stent is then anchored proximally with circumferentially placed interrupted pledgeted sutures. This technique is significantly less complex than a total or partial aortic arch replacement but retains the benefits of distal aortic stabilization, obliteration of the false lumen, and positive aortic remodeling. In their reported midterm results with an average follow-up of 3.9 years, Berdajs and colleagues ${ }^{4}$ observed an increased survival, a decreased risk for adverse events, and no difference in need for aortic interventions in patients treated with a modified frozen elephant trunk technique compared with their control group of isolated hemiarch replacement. Despite the promising midterm results, it is important to note that Berdajs and colleagues ${ }^{4}$ started using the modified frozen elephant trunk technique in 2009 and that it has been their standard approach since 2013. Patients treated with a modified frozen elephant trunk were thus disproportionately represented later in the study period than the control group. As we have repeatedly observed within the literature, many centers have had improved 